\title{
Air embolism after percutaneous transhepatic biliary drainage and subsequent endoscopic retrograde cholangiopancreatography (ERCP)
}

A 45-year-old man presented with a 5-day history of obstructive jaundice. The patient underwent an initial attempt at endoscopic retrograde cholangiopancreatography (ERCP), however the common bile duct was inaccessible. He then underwent percutaneous biliary drainage. A guide wire was left positioned in the duodenum, and the patient was transferred from radiology to the endoscopy unit for ERCP. An endoscope was passed and the previously placed guide wire was visualized at the ampulla. A cholangiogram showed multiple filling defects in the common duct. At this point there was clear access to the duct endoscopically and the percutaneous guide wire was removed. There was some initial bleeding from the percutaneous site, but pressure was applied for hemostasis. A basket was used to attempt to clear the common bile duct, but at this point fresh clot came from the papilla. A stent was placed and the procedure was terminated. The patient then became profoundly bradycardic and cardiopulmonary resuscitation (CPR) was initiated. He required cardioversion for ventricular tachycardia and a transesophageal echocardiogram was carried out. This showed clear evidence of pulmonary outflow obstruction as well as a patent foramen ovale (PFO), with air being shunted from the right to the left. However, the patient's vital signs stabilized without any further intervention. On brain magnetic resonance imaging (MRI) the patient was found to have multiple areas of acute infarction in the frontal, parietal, and occipital lobes, consistent with an embolic event. He initially had a moderate functional deficit but has eventually regained near complete recovery. Another patient with a similar presentation and percutaneous transhepatic cholangiography (PTC) drainage underwent subsequent ERCP. Again, a blood clot was retrieved from the ampulla. Owing to the possibility of a biliary-vascular fistula, a sphincterotomy was not carried out but a stent was placed. The PTC catheter remained in place until completion of the procedure which was uneventful and well tolerated. Thus if a blood clot is apparent on ERCP after percutaneous transhepatic biliary drainage or other hepatic intervention, there should be a high index of suspicion for air embolism and precautions should be taken accordingly [1-5]. In the second case reported here, by leaving the PTC catheter in place until the endoscopic procedure was terminated and deferring sphincterotomy to a later time, the potential for air embolism may have been reduced and possibly prevented.

Endoscopy_UCTN_Code_CPL_1AK_2AH

Competing interests: None

G. Maccarone, T. Shakoor, B. Ellis

Department of Surgery, Good Samaritan Hospital, Cincinnati, Ohio, USA

\section{References}

1 Cha ST, Kwon CI, Seon HG et al. Fatal biliarysystemic air embolism during endoscopic retrograde cholangiopancreatography: a case with multifocal liver abscesses and choledochoduodenostomy. Yonsei Med J 2010; 51: 287-290

2 van Boxel GI, Hommers CE, Dash I et al. Myocardial and cerebral infarction due to massive air embolism following endoscopic retrograde cholangiopancreatography (ERCP). Endoscopy 2010; 42 (Suppl. 2): E80-81

3 Finsterer J, Stöllberger C, Bastovansky A. Cardiac and cerebral air embolissm from endoscopic retrograde cholangio-pancreatography. Eur J Gastroenterol Hepatol 2010; 22: $1157-1162$

4 Nayagam J, Ho KM, Liang J. Fatal systemic air embolism during endoscopic retrograde cholangio-pancreatography. Anaesth Intensive Care 2004; 32: 260 - 264

5 Romberg C. Systemic air embolism after ERCP: a case report and review of the literature (with video). Gastrointest Endosc 2009; 70: $1043-1045$

\section{Bibliography}

DOI 10.1055/s-0030-1256943

Endoscopy 2011; 43: E399

(c) Georg Thieme Verlag KG Stuttgart · New York . ISSN 0013-726X

Corresponding author

G. Maccarone

Good Samaritan Hospital

375 Dixmyth Ave

Cincinnati

OH 45220

USA

Fax: +513-862-1549

gina.maccarone@gmail.com 